\title{
Building the Knowledge Economy
}

\author{
Vlatko Čerić \\ Graduate School of Economics \& Business, University of Zagreb, Croatia
}

\begin{abstract}
Generation and exploitation of knowledge became one of the most significant components in the new economy. This paper first investigates influence of information and communications technology on economy, with specific emphasis on Internet economy and electronic commerce. The paper then describes characteristics of the knowledge economy, discusses knowledge, presents main issues relevant for building of knowledge economy and gives an overview of the situation and perspectives of knowledge economy in Europe.
\end{abstract}

Keywords: knowledge economy, information and communications technology, Europe

\section{Introduction}

In the last two decades information and communications technology (ICT) made a major influence on all areas of business, as well as on personal and social life. Prices of ICT equipment were falling drastically through this period of time, which led to fast increase of installed computing and communication equipment in enterprises, government institutions and homes. New ICT systems for scanning, imaging, storage, computing and communications are developed continuously. Huge quantity of digitized material appeared, and a substantial number of applications were developed.

Introduction of Internet was a major step that reshaped economy by enabling global communication, as well as global transport of information and knowledge. Internet had an enormous influence in changing business models of enterprises, enabling cheap global publication and marketing, as well as cheap and fast business transactions between businesses, business and customer, government and customers, government and business, etc. (Victoria University, 2000).
Capital, energy, labour and land are no more the only factors in production, and creation of wealth is transformed from exclusively physicalbased work to increasingly knowledge-based work. Growing influence of information and knowledge on economy led to "knowledge economy", i.e. economy that is directly based on the production, distribution and use of knowledge and information (OECD, 1996). Several other names coined for the same phenomenon are information economy, new economy, digital economy, and network economy.

Second section of this paper deals with influence of information and communications technology on economy. Third section discusses knowledge economy in some detail, while the fourth section describes the main types of knowledge. Section five presents main issues in building the knowledge economy, while section six discusses some social issues related with knowledge economy. Section seven presents some facts related with development of knowledge economy in Europe, while the last section includes some conclusions.

\section{Influence of Information and Communications Technology on Economy}

Rapid development of information and communications technology and dramatic fall of ICT equipment prices in the last decade (e.g., annual fall of computer prices was about 12 percent between 1987 to 1994, and about 26 percent between 1995 and 1999) is having a fundamental influence on the economy as a whole. According to the (U.S. Department of Commerce, 
2000) real business investment in ICT equipment and software in U.S. increased from \$243 billion in 1995 to $\$ 501$ billion in 1999 . ICT industries account for 8.3 percent of U.S. economy output in 1999 and contributed for nearly a third of real U.S. economic growth between 1995 and 1999. In 1998 ICT industries invested almost one third of all company-funded research and development investment. In the second half of the 1990s the production and use of ICT contributed to more than a half of the acceleration of U.S. productivity growth.

Exceptionally strong influence of ICT on economy came from explosive growth of computer networks, and particularly Internet. Internet and World Wide Web enable companies of all sizes to radically improve interaction with customers and other businesses, build new products and services, and carry out business efficiently and globally. Private computer networks (intranets) enable exchange of important information within the enterprises, as well as cooperation between employees dispersed on very long distances. Outsourcing became much simpler, faster and cheaper, new ways of working (such as telework) emerge, while direct sales via Web and distribution of digital products via Internet led to dramatic fall of operation and distribution costs. Customers became able to compare product and service prices, and request personalization of products and services.

ICT industries also intensively influenced the creation of additional jobs in local economies e.g. in the Washington state in 1995 each job in the ICT giant Microsoft created 6.7 new jobs, while a job in Boeing created 3.8 new jobs.

Internet Economy, i.e. economy based on Internet, includes companies directly generating all or some part of their revenues from Internet or Internet-related products and services. Internet Economy can be classified into Internet infrastructure layer, Internet applications infrastructure, Internet intermediaries and Internet commerce layer. Recent study of the Center for Research in Electronic Commerce (University of Texas, 2001), that included worldwide Internet-based revenues of U.S.-based companies, showed that their overall annual revenue growth was $58.8 \%$ between the second quarter of 1999 and the second quarter of 2000. Internet revenue is one-fifth the size of non-Internet revenue, but growing three times as fast as corporate revenue in whole.

Total employment in Internet Economy grew $22.6 \%$ between the second quarter of 1999 and the second quarter of 2000. Internet Economy supported 3.088 million workers in mid-2000, including 600.000 new workers employed in the first half of 2000. Internet-related jobs in Internet Economy companies grew four times faster than the growth of the non-Internet related jobs in these same Internet Economy companies. Total number of employed people in Internet Economy was somewhat bigger than the number employed in insurance industry and double the number employed in real estate industry.

Internet Economy growth is unprecedented, surpassing even the extremely fast growth in personal computer industry. While personal computer industry grew from zero to $\$ 100$ billion in ten years, the Internet Economy grew from zero to $\$ 800$ billion in five years. Both business and customers are now using Internet routinely, as can be seen from the growth of Internet-related Christmas holidays spendings. These spendings grew from $\$ 4.2$ billion in 1999 to $\$ 8.7$ billion in 2000, according to a study by Goldman Sachs and PC Data.

Electronic commerce refers to all aspects of business that take place over computer networks (Adam et al, 1999; Čerić, 2001). These business activities may involve consumers, manufacturers, service providers and intermediaries. Electronic commerce includes goods and services that are delivered over the networks, as well as goods ordered over the networks and delivered by traditional delivery channels. It includes various business functions required to support these activities, such as marketing, production and delivery. Electronic commerce size is growing at an impressive speed - its annual revenue growth from second quarter of 1999 to second quarter of 2000 was $57.8 \%$ (University of Texas, 2001).

Electronic commerce radically changes the way organizations carry out business and enables substantial increase of speed and efficiency of business transactions. Communication and cooperation both inside the company and between companies and customers or other companies becomes much simpler and faster. Production and delivery costs are cut and delivery cost for digital products became negligible, while 
products are delivered almost instantaneously. Electronic marketplaces (Bakos, 1999) is a key economic infrastructure built around electronic commerce with rapidly growing influence and use.

\section{Knowledge Economy}

While the traditional economy perceived labour and capital as the only factors that influence the production and determine the standard of living, this approach has difficulties with dealing with the causes of long-term economic growth. New economic growth theories (see e.g. Romer, 1986) are therefore not viewing knowledge as an exogenous variable but rather as an intrinsic part of the economic system. Knowledge is regarded as the basic form of capital, and economic growth is driven by the accumulation of knowledge.

Technological progress, itself based on knowledge, was previously assumed to occur at a constant rate, but new growth theories relate its rate to government policies. Technological developments can create technical platforms for further innovations, and this is a key driver of economic growth (Ministry of Economic Development, New Zealand, 1999).

Growing importance of knowledge in economy led to the notion of knowledge economy, that can be defined as "one in which the generation and exploitation of knowledge has come to play a dominant role in the creation of wealth" (Web: Department of Trade and Industry, UK). There are several reasons that influence the growing importance of knowledge on economic progress: (1) progress in information and communications technology that enables inexpensive and fast global transport of information and access to knowledge, (2) increased speed of scientific and technological advance that led to acceleration of growth of quantity of explicit scientific and technological knowledge, (3) increased global competition that led to reduced costs, and (4) changing demand associated with rising incomes and change of tastes of citizens.

Digital technologies make processing, storage and accessing of information increasingly cheaper and easier. Huge quantities of information influence operation of businesses and markets, and lead to creation of wealth through exploitation of information.

Some industries have knowledge as their main product, while many other industries manage or transport information. Industries that produce knowledge include software, hardware and biotechnology industries, and some important occupations in these industries are scientists, engineers or programmers. These industries make up less than 7 percent of economy output, but are key drivers of knowledge economy.

Knowledge-based products appear in the form of knowledge goods, digitized processes, digitized physical goods, and knowledge-enhanced physical goods and services (Choi and Whinston, 2000). Knowledge goods include goods that can be digitized and transferred over computer network, like magazines, books, photographs, or music. Digitized processes are products or services that rely on providers that have specialized knowledge, like information search service that reorganized a service function into a knowledge-based product. Digitized physical goods is anything that can be digitized and sent over computer network, like news, postcards, instructions, tickets or government forms. Knowledge-enhanced physical goods and services are built around products that cannot be digitized but have some components that are knowledge-based, like control of home security and appliances that is done by software.

Many more industries are managing, processing or distributing knowledge, such as banking, insurance, education, law, medicine or government. Some of the typical occupations in these industries are bankers, teachers, lawyers or sales representatives. In these industries efficient processing and management of information is key to their success.

Here are some interesting facts related to knowledge economy:

About $70 \%$ of the production cost of a new car can be attributed to knowledge-based elements such as styling and software (Scottish Enterprise, 1998). A modern luxury car includes more computer power than Apollo 11.

The value-added generated by knowledge-based industries in the OECD increased at an annual average rate of 7 per cent between 1985 and 1994, while the figure for a business sector as a whole was just over 5 per cent.

In advanced economies more than 60 percent of workers are knowledge workers, i.e. workers who 
manipulate symbols rather than machines. This type of workers includes designers, teachers, researchers, architects, and various computer-related professionals.

\section{Types of Knowledge}

A large amount of information is being created and stored, but it doesn't mean that it is automatically turned into knowledge. Information becomes knowledge only when it has been read and understood by somebody, who may use this knowledge for action or thought. Different persons, having different previous experience, will interpret and use the same information in different ways.

Two types of knowledge can be distinguished: codified (explicit) and tacit knowledge (OECD, 1996; Nonaka and Takeuchi, 1995). Codified knowledge is knowledge gained by formal education and training. This type of knowledge can be precisely described and transferred to other people. Tacit knowledge is knowledge gained by experience - it needs a lot of time to be achieved by somebody and it is much more difficult to transfer to other people. Example of tacit knowledge is an expert's understanding of how some complex system operates or how a particular technology can be used in various circumstances. Tacit knowledge can be as important for economic purposes as explicit knowledge.

Knowledge can also be categorised in another way (OECD, 1996). Know-what is knowledge about facts, while know-why is knowledge about principles that govern natural and social phenomena, knowledge that is learned in formal education. Know-how is different, since it refers to skills, i.e. the ability to do practical things. Know-who is knowledge about who knows what and who can do what, and this type of knowledge is also very useful in practice as well as know-where some important information can be found. All these types of knowledge can be useful for economic purposes.

Knowledge can be stored in various media (Armour, 2000). Tacit knowledge is stored in human brain, while codified knowledge was traditionally stored in books and journals. In the last fifty years a new medium for storage of codified knowledge appeared - this medium is software. Software has unique combination of desired characteristics: it is persistent, quick to update, and active. Active property of software means that software, which can be easily and quickly spread on huge distances, can be applied to action simply by executing it (examples are business activities, technical or scientific calculation, or chess playing). Because of its valuable characteristics, a huge and rapidly growing quantity of knowledge from all possible sources is progressively being translated into this medium.

\section{Main Issues in Building the Knowledge Economy}

Investments can make technology more valuable, but this can lead to sustained GDP growth only if the country has a sufficient human capital. This means that formal education, training and on-the-job learning are essential for obtaining skilled workforce and management, and thus advancing the economy and achieving prosperity. This also means better training of teachers, development of modernised curricula and better-equipped schools. Lifelong learning is also extremely important for advancing the knowledge of individuals, enabling them to change occupation and enabling enterprises to get enough workers with appropriate education.

Besides that, the right environment for innovation and the exploitation of new ideas has to be created (Web: Department of Trade and Industry, UK). This means attainment of macroeconomic stability, protection of intellectual property rights, development of strong banking and financial systems capable of bearing risk, and development of social environment supportive for development of enterprises. The role of the government is also to encourage investments in basic science and in new technology, to develop technical education, as well as establish the right regulatory environment and setting technical standards.

Stronger direct links between business and academic world should be developed, and enterprises should make more use of scientists and engineers as a source of expertise. For example, some thousand companies related with Massachusetts Institute of Technology have annual worldwide sales of about $\$ 53$ billion. 
Managers in firms must be able to manage the innovation process, improve quality of products and services and position products on the market. Special importance should be paid to the field of knowledge management, i.e. management of production, sharing and using the knowledge capital in organizations. Different knowledge management technologies (Borghoff and Paresi, 1998) are developed for this purpose, such as knowledge discovery and data mining, search for information in the vast Web information space (Čerić, 2000), knowledge representation methods, use of knowledge in expert systems and simulation models, network communication and cooperation tools, etc.

\section{Social Issues Related to Knowledge Economy}

Knowledge economy, and especially information and communication technologies, poses various social challenges (National Research Council, 1998). Here is a list of some of them:

- Influence of information and communications technology on private life and loosing of privacy.

- Employment has become less certain and stabile than in the past, and also more dependent on high skills.

- Problem of intellectual property protection in networked economy.

- New ways of working, e.g. telework in which work is carried out independent of location, have definite benefits for workers and the environment. However, they also lead to significant change in the nature of work (e.g. social isolation) and needs appropriate legislation and framework that guarantees rights and obligations for teleworkers and their employer.

- Digital divide, i.e. persistence of divide between information rich that have higher incomes and are more educated and information poor who are younger, have lower income and education levels, are minorities and live in rural areas or in centres of big cities.

\section{Europe and Knowledge Economy}

\section{European Union}

European Union is lagging behind the US in electronic commerce and knowledge economy, although it has some significant advantages over US (Web: European Commission).

Internet penetration rates in EU are 2-3 times lower compared to US, and inside EU these rates are highly variable. Number of European hosts is less than a third of the number of hosts in the US, and very few of European Web sites appear in the list of most popular Web sites. Shortage of venture capital in the EU leads to smaller number of European start-up companies and fewer online services for European users. Price for Internet access is higher, primarily because of lack of proper competition in the local loop.

Only $16 \%$ of EU workers have received ICT training paid by their employers. Software, services and telecommunications sector continue to increase overall employment by $10 \%$, but supply for ICT skills is not matching demand. Up to 1.7 million jobs may be unfilled if the supply doesn't rise fast enough.

Europe has large social and regional discrepancies. As an example, PC penetration in homes ranges from $11 \%$ to $65 \%$, while Internet penetration ranges from $3 \%$ to $51 \%$. Only about $25 \%$ of Internet users are women, compared to about $50 \%$ in the US. Low Internet usage in some parts of Europe presents both a social and an economic problem, since it reduces the size of the market as well as the growth potential of the economy.

Some of the key Europe's strong points are the following:

- Good education system

- ICT skills accreditation system called European Computer Driving Licence (ECDL) that is used in many EU member countries

- Some of the European technological strengths are in wireless telephony, smart cards and interactive television. Mobile device penetration is higher than in the US and is growing very fast.

- $45 \%$ of EU workers and $73.5 \%$ of white collar workers use computers for their job 
- ICT industry in Europe represents $6 \%$ of GDP and is growing much faster than other sectors.

In order to become a major player in knowledge economy EU is increasing its efforts in the development of information society via the eEurope framework. This includes numerous measures for improvement of ICT education, competition in local loop, increasing venture capital, etc.

One important fact is that because new ICT companies make strong e-commerce brands, market entry may soon become very costly. For this reason it is critical to take action fast since the chance of succeeding on the market may soon be lost.

Some examples of Europe's steps in creating stronger knowledge economy are:

Percentage of European households connected to the Internet has grown in the last year from 18 percent to 30 percent.

Number of European patents has grown by 75 percent in the last five years.

Nokia help funded a research centre at Tampere University that became one of the world most advanced laboratories for telecommunications.

Leuven University developed the Leuven Research and Development Centre by expanding its own venture capital in collaboration with two largest banks. As a result, twenty start-up companies were created in the past three years. A team of lawyers, patent experts, economists and engineers employed by the university help draw up plans for students who want to become entrepreneurs.

\section{Central and Eastern Europe}

Central and Eastern European (CEE) countries are in the decade-long painful transition period from the state toward the market economy. Several CEE countries are rather advanced in economic reforms and development of information and communications technology, while most of the others are far behind the EU member states. One of the consequences of the poor economic situation, lack of developed communications infrastructure and lack of competition in telecommunication area is that CEE significantly lags behind EU in all measures of Internet access and use (Web: Center for Democracy and Techno$\log$ ).

Digital divide in CEE countries is very deep, and this fact is extremely damaging from both the social and the economic viewpoint because of the very low level of GDP per capita.

Besides the necessity for drastic economic reforms in CEE countries, there is also a clear need for development and implementation of national ICT strategies that will take into account both strong and weak points of the country, and will be directed toward basically the same goals as EU member states. Otherwise, a lack of focus in technological and economic development can be expected to dissipate scarce resources that these countries possess. An example of the national strategy in Central and Eastern Europe is the recently finished Croatian ICT strategy (Budin et al, 2001) that seeks to use Croatian potentials and strong points to achieve the same basic goals as EU countries.

\section{Conclusions}

Knowledge economy, i.e. economy based on the production, distribution and use of knowledge and information, is heavily based on information and communications technology (ICT). Increased speed of ICT advancements, and especially dramatic growth of Internet and its services, as well as continuous decline of ICT equipment prices, led to fast growth of both Internet and the number of its users. All these were instrumental in the growth of influence of knowledge and information on economy.

However, some other prerequisites besides technology must be fulfilled too in order to enable growth of knowledge economy. First of them are education and training, including lifelong learning, training of teachers and developing modernised curricula. Besides, proper environment for innovation should be created and stronger links between business and academic world should be developed. Managers in enterprises should be able to manage the innovation process, and special importance should be paid to the field of knowledge management, i.e. management of production, sharing and use of knowledge capital in organization.

Attention should also be devoted to social issues related to knowledge management, e.g. to the influence of ICT on private life and loosing privacy, as well as its influence on certainty of 
employment in telework. Problems of intellectual property protection are specially sensitive in the era of networks. Finally, an extremely serious problem is digital divide, i.e. problem of divide between information rich and information poor. Digital divide is damaging from both the social and the economic viewpoint. This problem appears also in European Union, and it is specifically tough in Central and Eastern Europe because of the very low level of GDP per capita in these countries.

\section{References}

[1] ADAM, N. R. ET AL (1999), Electronic Commerce: Technical, Business, and Legal Issues, Prentice Hall, Upper Saddle River, NJ.

[2] Armour, P. G. (2000), The Case for a New Business Model: Is Software a Product or a Medium, Communications of the ACM 43, 8, 19-22.

[3] BaKos, Y. (1999): The Emerging Role of Electronic Marketplaces on the Internet, Communications of the ACM 41, 8, 35-42.

[4] Borghoff, V. AND R. PAREsi (1998) (Eds.), Information Technology for Knowledge Management, Springer Verlag, New York.

[5] BUDIN, L. ET AL (2001), Strategy of Information and Communications Technology in Croatia, Part of the Strategy of Development of Republic of Croatia: Croatia in the 21st Century, Zagreb, online at http://www.hrvatska21.hr/

[6] CHOI, C-Y. AND A. B. Whinston (2000), The Internet Economy: Technology \& Practice, SmartEcon Publishing.

[7] ČERIĆ, V. (2000), New Methods and Tools for the World Wide Web Search, Journal of Computing and Information Technology - CIT 8, 267-276.

[8] ČERIĆ, V. (2001), Internet Economy and Electronic Commerce, Zbornik radova - Journal of Information and Intelligent Systems, accepted for publication.

[9] Ministry of Economic Development, New Zealand (1999), The Knowledge Economy, August 1999 online at http://www.med.govt.nz/pbt/ infotec/h/knowledge_economy/

[10] National Research Council (1998), Fostering Research on the Economic and Social Impacts of Information Technology, National Academy Press, Washington, D. C., 1998.

[11] NEEF, D. (1997), The Knowledge Economy, Butterwords-Heinemann, Boston.

[12] NonAKA, I. AND H. TAKEUCHI (1995), The Knowledge Creating Company, Oxford University Press, Oxford.
[13] OECD (1996), The Knowledge Economy. In Science, Technology and Industry Outlook, Paris.

[14] RoMER, P. M. (1986), Increasing returns and LongRun Growth, Journal of Political Economy 98 (5), 1002-1037.

[15] Scottish Enterprise (1998), The Clusters Approach: Powering Scotland's Economy into the $21^{\text {st }}$ Century.

[16] University of Texas (2001), Measuring the Internet Economy, January 2001, online at http://www. internetindicators.com

[17] U.S. Department of Commerce (2000), Digital Economy 2000, June 2000 online at http://www.esa.doc.gov/de2000.pdf

[18] Victoria University (2000), A Primer on the Knowledge Economy, online at http://www.cfses.com/primer.htm

\section{Web References}

[1] Center for Democracy and Technology Bridging the Digital Divide, http://www . cdt.org /international/ceeac|ces|s/

[2] Department of Trade and Industry, UK, Building the Knowledge Driven Economy: Analytical Report, http://www.dti.gov.uk/comp/competitive /main.htm

[3] European Commission, eEurope 2002 Action Plan, June 2000, http: //europa. eu. int/ information_society/eeurope /action_plan/index_en.htm

Received: June, 2001 Accepted: September, 2001

Contact address:
Vlatko Čerić
Graduate School of Economics \& Business, University of Zagreb
Kennedyjev trg 6
10000 Zagreb
Croatia
Phone: +38512383280
Fax: +38512335633
e-mail: vceric@efzg.hr

DR. VLATKO ČERIĆ is a professor and head of Department of Computing at the Graduate School of Economics \& Business, University of Zagreb. His main research interests are simulation modelling, decision support systems, information retrieval, electronic commerce, knowledge economy and operations management. He published over 80 papers and several books, and was a leader of several research and application oriented projects. 